\title{
AGRICULTURA FAMILIAR: SUA RELEVÂNCIA PARA O BRASIL, O ESTADO DE MATO GROSSO DO SUL E O MUNICÍPIO DE PONTA PORÃ
}

\author{
Carlos Otávio Zamberlan ${ }^{1}$ \\ Karoline Cavalcanti
}

\begin{abstract}
RESUMO
A agricultura foi a base da organização produtiva no Brasil durante praticamente toda sua história, apenas no século $X X$, com o processo de industrialização essa realidade começa a mudar. Todavia, a agropecuária exerceu papel importante na segurança alimentar e na geração de divisas. A agricultura familiar, que congrega um conjunto de indivíduos de uma família em unidades produtivas para o autoconsumo e também para o mercado, tem seu papel nesse contexto. Esse artigo tem como objetivo analisar a relevância produtiva de alimentos que compõem a alimentação do Brasileiro por parte da agricultura familiar para o Brasil, para o estado de Mato Grosso do Sul e, em particular, para o município de Ponta Porã. Por meio de um estudo baseado em publicações científicas e levantamento de dados do Censo agropecuário e da Produção Agropecuária Municipal, fornecidos pelo Instituto Brasileiro de Geografia e Estatística (IBGE), pode-se constatar a importância da lógica de produção familiar nas esferas analisadas, mas salienta-se a necessidade de rever as definições acerca da agricultura familiar para não tomá-la com menor importância, quando associada a conceitos sem adequada fundamentação que podem levar a uma impressão errônea de sua importância e de sua participação na produção de alimentos.
\end{abstract}

Palavras-chaves: Agricultura familiar, campesinato, segurança alimentar.

\section{FAMILY FARMING: ITS RELEVANCE TO BRAZIL, THE STATE OF MATO GROSSO DO SUL AND THE MUNICIPALITY OF PONTA PORÃ}

\begin{abstract}
Agriculture was the basis of the productive organization in Brazil for almost all of its history, only in the twentieth century, with the process of industrialization this reality begins to change. However, agriculture has played an important role in food security and in the generation of foreign exchange. Family farming, which brings together a group of individuals from a family into productive units for self-consumption and also for the market, plays its role in this context. This article aims to analyze the productive relevance of foods that make up the Brazilian diet by family farming for

1 Graduado em Administração (UFSM). Especialização em Gestão Empresarial (UFSM). Mestrado em Administração (UFSM). Doutorado em Economia (UFRGS). Professor do Programa de Pós-Graduação em Desenvolvimento Regional e de Sistemas Produtivos (PPGDRS) da Universidade Estadual de Mato Grosso do Sul (UEMS). E-mail: otaviozamberlan@gmail.com

${ }^{2}$ Graduada em Ciências Econômicas (UFSM). Aluna Especial do Mestrado em Desenvolvimento Regional e de Sistemas Produtivos (PPGDRS) da Universidade Estadual de Mato Grosso do Sul (UEMS). E-mail: karolcavalcanti@hotmail.com
\end{abstract}


Brazil, for the state of Mato Grosso do Sul and, in particular, for the municipality of Ponta Porã. Through a study based on scientific publications and data collection from the agricultural and livestock senses and Municipal Agricultural Production, provided by the Brazilian Institute of Geography and Statistics (IBGE), one can verify the importance of the logic of family production in the analyzed spheres, but it is necessary to revise the definitions about family agriculture so as not to take it with less importance when associated with concepts without adequate rationale that may lead to an erroneous impression of their importance and their participation in food production

Key-Words: Family farming, peasantry, food security.

\section{INTRODUÇÃO}

No Brasil a agricultura sempre foi considerada um importante setor que contribuiu de forma significativa para a formação econômica e cultural do país. O setor agrícola, desde longo período, ocupa posição determinante nas exportações brasileiras e participação essencial no Produto Interno Bruto (PIB) da economia. "Esse fator contribui para o desenvolvimento social e econômico de toda a Nação, pois além de gerar renda e emprego no meio rural, gera também a todos os setores da economia." (OLIVEIRA, 2010, p. 2)

Incorporado ao setor agrícola, a agricultura familiar representa papel fundamental para a relevante participação do setor a nível nacional. No contexto brasileiro, a agricultura familiar passa a ser discutida nos anos de 1990, mas deixa de ser vista como sinônimo de atraso em período mais recente, passando a ser compreendida como elemento chave para o desenvolvimento regional (STALOCH e ROCHA, 2018).

De acordo com informações do Ministério do Desenvolvimento e Combate a Fome, indicadas por Oliveira et al. (2010, p. 2) no artigo "Agricultura Familiar do agronegócio do leite em Rondônia, importância e característica", a agricultura familiar "(...) é responsável por mais de $40 \%$ do valor bruto da produção agropecuária, correspondem a mais de $74 \%$ da mão-de-obra ocupada nas propriedades rurais do país, além de responder pela maioria dos alimentos na mesa dos brasileiros". Além disso, a agricultura familiar, conforme apontam Conti, Bazotti e Radomsky (2015), auxilia a contribuir para viabilizar meios de vida na ruralidade e, ainda, oportuniza sinergias e aproximações entre o rural e o urbano na produção e consumo alimentar.

Dada a síntese da importância da agricultura familiar no contexto nacional, o estudo tem por objetivo evidenciar a existência dessa relevante atividade para o estado sul mato-grossense considerando, também, sua relevância para o município de Ponta Porã, em particular. Para atingir o objetivo discutido foi necessário um levantamento da literatura específica e análise de dados do Censo Agropecuário, publicado pelo Instituto Brasileiro de Geografia e Estatística (IBGE).

Este estudo está organizado em 5 (cinco) seções considerando essa introdução. Na segunda seção busca-se formar um entendimento sobre o que é a agricultura familiar, pois não existe uma conceituação universal do termo. Na terceira seção, discutem-se os materiais e métodos. A quarta seção traz a sua importância para o Brasil, Mato Grosso do Sul e município de Ponta Porã. A quinta e última seção são abordadas as considerações finais. 


\section{O QUE VEM A SER AGRICULTURA FAMILIAR?}

O termo "agricultura familiar", anteriormente denominado como agricultura de subsistência, consiste em um modo de produção dos setores "agrícola, florestal, pesqueiro, pastoril e aquícola", segundo a Food and Agriculture Organization of the United Nations - FAO (2014), no português, Organização das Nações Unidas para Alimentação e a Agricultura, considera-se como agricultura familiar a produção desenvolvida e administrada por membros de uma família, podendo conter até dois empregados registrados. Todavia, essa conceituação é muito abrangente, pois não limita a unidade de produção na consideração de agricultura familiar. Não considerar limites de área da unidade produtiva parece não ter significado algum, pois se for considerado o trabalho familiar aplicado às atividades agropecuárias se está abordando a chamada agricultura familiar, não é verdade? Não, pois não dar limites a área explorada pode abranger nas análises latifúndios improdutivos e se estaria dando um viés significativo às análises, pois se correria o risco de não mensurar a produtividade real dos agricultores familiares.

Então é conveniente buscar outros conceitos a fim de melhor entender essa terminologia. Para Schneider (2003) a agricultura familiar é entendida como um conjunto de indivíduos que passam a formar um grupo doméstico detentor da posse e da exploração de uma mesma propriedade, que se constitui em uma unidade de produção e consumo. Essa afirmação ainda carece de limitar a área da unidade produtiva, mas traz um elemento que dá um caráter significativo, ou seja, a produção para consumo, mas que não se detém apenas a ele. Isso significa que a produção na agricultura familiar pode estar voltada para a subsistência e/ou para o mercado, não se restringindo a uma ou outra.

Nessa mesma linha de raciocínio Wanderley (2003) ao trazer diversas abordagens existentes no contexto acadêmico sobre agricultura familiar, incluindo uma visão que pressupõe o abandono do campesinato e o enfoque ao mercado, portanto um caráter modernizado que, passa a centrar a agricultura familiar como sendo aquela que tem suas bases na lógica familiar herdada do campesinato, que pode ser de pura subsistência ou mesclar com produção voltada ao mercado, portanto mais moderna. Todavia, percebe-se uma tradição da agricultura camponesa sendo mantida, mesmo que exista o direcionamento ao mercado.

No Brasil, no campo político, a agricultura familiar ganha contornos de definição mais por questões políticas e menos através de uma concepção teórica, mas visando atender a um segmento de agricultores que necessitavam de políticas públicas até então ausentes. O Programa de Apoio à Agricultura Familiar (PRONAF), criado em meados da década de 1990, pelo governo Fernando Henrique Cardoso, trata de colocar requisitos para enquadrar o agricultor na categoria de familiar, tornando-se imprescindível a Declaração de Aptidão ao Pronaf (DAP), sendo que nela constam as informações relacionadas ao imóvel rural, renda familiar, além de informações sobre os donos da terra, entre outras, que darão segurança jurídica para as transações de crédito e financiamento. Em 2006 o enquadramento do agricultor familiar será aprimorado na lei 11.326.

De acordo com a lei 11.326/2006 "o agricultor ou empreendedor familiar rural deve enquadrar-se nos seguintes critérios: i) não deter, a qualquer título, área maior do que 4 (quatro) módulos fiscais; ii) utilizar predominantemente mão de obra da própria família nas atividades econômicas do seu estabelecimento ou empreendimento; iii) tenha renda familiar predominantemente originada de atividades econômicas vinculadas ao próprio estabelecimento ou empreendimento; iv) dirigir seu estabelecimento ou empreendimento com sua família" (BRASIL, 2006). 
Um ponto que se deve levar em consideração é a questão de que a lei não possui um embasamento teórico consistente, e que sustente as características de que um agricultor familiar é só quem se enquadra na lei. Para Alfatin (2007), a opção adotada para delimitar o público foi o uso "operacional" do conceito, centrado na caracterização geral de um grupo social bastante heterogêneo.

Navarro (2010 apud MOURA, 2011) critica a aplicação normativa alegando que:

Não há, de fato, nenhuma justificativa teoricamente razoável para caracterizar agricultores familiares também adicionando aqueles critérios citados nos preceitos legais. Como já mencionado, o Pronaf e seus indicadores e, posteriormente, a Lei 11.326, agregaram requerimentos que atendiam, particularmente, a imperativos políticos e demandas sindicais de enquadramento, os quais não se sustentam em nenhuma inteligibilidade teórica decorrente de um conceito de agricultura familiar (e, menos ainda, em alguma "teoria da agricultura familiar"). (NAVARRO, 2010, apud MOURA, 2011, p.20).

A lei apresentada expressa fatores característicos quanto ao perfil do atual agricultor familiar. No entanto, o conceito não deve ser analisado de forma engessada aos pontos estabelecidos. Há situações em que nem todos esses critérios são enquadrados. O fundamento da agricultura familiar deve, nesse sentido, ser pautado na importância da atividade para a família, ou seja, se a atividade é representada pela participação da família, se compreende dedicação total e exclusivamente para práticas agrícolas familiares e é por meio desta atividade que adquirem o sustento. Além disso, devem-se buscar métodos que incluam grande parte das propriedades que possuem tais características, mas que não se enquadrem como latifúndios, optando por uma limitação de área. No entanto, essa limitação ainda sofre da necessidade de definição.

Há várias vertentes e definições que conceituam a agricultura familiar, que divergem ou não entre si. De acordo com Moura (2011), em resumo, a agricultura familiar está fundamentada em três conceitos: "gestão da propriedade, organização do trabalho e propriedade dos meios de produção". Além disso, pode-se, para efeitos de análise, limitar o tamanho das unidades de produção a fim de excluir o que se entende por latifúndios, que perderiam características advindas da lógica da produção familiar.

\section{MATERIAIS E MÉTODOS}

Esta seção faz uma breve consideração sobre os materiais e métodos utilizados para a elaboração deste estudo. Primeiramente caracteriza-se a pesquisa quanto aos objetivos e os procedimentos metodológicos. Somente após essa caracterização apresenta-se o método de coleta e análise de dados.

Este artigo se caracteriza, quanto aos objetivos, como um estudo exploratório-descritivo. Exploratório, pois busca formar uma compreensão sobre o tema da agricultura familiar, que não possui uma definição universalmente aceita. Descritivo, pois busca descrever a importância da agricultura familiar, baseada nos preceitos advindos da parte exploratória, tendo como elementos de descrição os dados oriundos do Censo Agropecuário de 2006 e a Produção Agrícola Municipal, ambos do Instituto Brasileiro de Geografia e Estatística (IBGE).

Quanto aos métodos foram utilizados a pesquisa documental, e o levantamento em dados secundários disponibilizados pelo Instituto Brasileiro de 
Geografia e Estatística (IBGE), nas pesquisas do Censo Agropecuário de 2006, utilizando os documentos revistos no ano de 2009, e da Pesquisa sobre Produção Agropecuária Municipal, para o município de Ponta Porã-MS. Esse município foi escolhido por ser ele que detém o maior assentamento do Brasil e, que, portanto, possui uma grande presença de agricultores familiares dentro do estado com menor presença deste modo de produção no Centro-Oeste brasileiro. A escolha pelo estado de Mato Grosso do Sul, se deu justamente por essa característica, ou seja, ser aquele que possui pouca presença do modo de produção familiar dentre os estados que compõem a região Centro-Oeste (exceto o Distrito Federal) e da região Centro-Oeste ser aquela que possui a mais baixa presença deste modo de produção no Brasil.

Os dados secundários referentes à produção familiar foram tratados com frequência relativa. A definição de agricultura familiar utilizada foi pela própria lei 11326/2006, que possibilitou comparar resultados de outros trabalhos que utilizaram essa definição e que trata a agricultura familiar dentro de 4 módulos fiscais. Também foi utilizado o limite de área inferior a 100 hectares para fins de comparação entre definições sobre agricultura familiar, área essa que caracteriza pequenas propriedades rurais, pois está abaixo dos padrões dos estudos da FAO/INCRA de 1996 citado por Guanziroli et al. (2001). Em trabalho publicado na Revista de Economia e Sociologia Rural, Guanziroli, Buainain e Sabbato (2012) utilizam limites de área que variam desde 279,3 hectares na região Sul até 1.155,2 hectares na região Norte. Na região Centro-Oeste, o limite de área é 650,7 hectares, para caracterização da agricultura familiar, considerando também aspectos de mão de obra.

A lei $11326 / 2006$ caracteriza como propriedade familiar aquelas que não ultrapassam 4 módulos fiscais; portanto, pode ser fator limitante na definição de agricultura familiar para algumas regiões brasileiras, onde o módulo rural é de 5 a 10 hectares. A intenção de fazer uma análise com uma concepção diferente do que aborda a referida lei recai sobre a necessidade de verificar se uma abordagem que busca um diferencial de conceito pode trazer resultados diferentes.

Além disso, a abordagem em 4 (quatro) módulos fiscais pode deixar muitos agricultores familiares de fora, onde os municípios possuem módulos com tamanho reduzido, por exemplo, inferiores a 10 hectares. O que se propõe é analisar além do que aborda a lei 11326/2006, pois se julga que ela é limitante por questões de financiamento e não por definição teórica. Mesmo assim se estabelece um limite para a propriedade a fim de se ter uma referência. Esse limite foi estabelecido para não correr o risco de incluir propriedades improdutivas nas análises, o que traria um viés às interpretações. Considerando as propriedades familiares com área inferior a 100 hectares procurou-se agrupar produtos hortigranjeiros que não aparecem em análises de outros estudos, que consideram como produtos da agricultura familiar somente aqueles selecionados pelo Instituto Brasileiro de Geografia e Estatística e associados a lei 11326/2006. No entanto, sabe-se que a agricultura familiar possui tradição na produção de hortigranjeiros e o agrupamento de pequenos produtores com menos de 100 hectares e atribuindo a eles a característica de familiar possibilitou uma proxy para as análises desses produtos anteriormente não considerados.

Para efetuar uma discussão sobre a importância da agricultura familiar continuou-se a abordar a literatura sobre o tema juntamente com as análises descritivas acima referidas. 


\section{IMPORTÂNCIA DA AGRICULTURA FAMILIAR PARA O BRASIL, MATO GROSSO DO SUL E PONTA PORÃ}

Esta seção busca abordar a importância da agricultura familiar para o Brasil e, principalmente para a cidade de Ponta Porã, localizada no estado do Mato Grosso do Sul. Faz-se, primeiramente, uma subseção que trata da agricultura familiar no Brasil com base em publicações e nos dados do censo agropecuário do IBGE. Posteriormente, em uma segunda subseção a agricultura familiar é tratada para o estado do Mato Grosso do Sul e, em particular, para a cidade de Ponta Porã.

\subsection{AGRICULTURA FAMILIAR: RELEVÂNCIA PARA O BRASIL}

Esta subseção tem o intuito de discutir a relevância da agricultura familiar para o Brasil, de forma geral. Busca-se informações sobre pessoas ocupadas, unidades de produção, participação dos produtos oriundos da agricultura familiar na alimentação interna para posteriormente tecer algumas considerações.

Segundo informações do Ministério do Desenvolvimento Agrário (2014) a agricultura familiar emprega aproximadamente 12 milhões de pessoas e é responsável por cerca de $70 \%$ dos alimentos consumidos no Brasil. Essa última informação foi contestada por Hoffmann (2014), em seu artigo intitulado "A agricultura familiar produz $70 \%$ dos alimentos consumidos no Brasil?" onde ele discorda dessa afirmativa tendo como base informações do censo agropecuário de 2006 e alicerçando suas análises na lei 11326/2006 para definir as unidades da agricultura familiar. Hoffmann, apesar de criticar esse dado, por não encontrar valores parecidos, não deixa de salientar a importância que a agricultura familiar possui, mesmo não tendo considerado produtos hortifrutigranjeiros, sabidamente oriundos, em grande parte dos agricultores de base familiar. As variáveis selecionadas no estudo de Hofmann (2014) são as demonstradas na Tabela 1.

Tabela 1 - Agricultura familiar segundo as variáveis selecionadas (2006)

\begin{tabular}{c|c|cc}
\hline Variáveis selecionadas & $\begin{array}{c}\text { Agricultura } \\
\text { familiar - Lei no } \\
11.326\end{array}$ & Não familiar & $\begin{array}{c}\text { Participação da AF } \\
\text { no Total da } \\
\text { Produção }\end{array}$ \\
\hline
\end{tabular}

\section{Produção vegetal}

\section{Arroz em casca}

Estabelecimentos

Quantidade produzida $(\mathrm{kg})$

Área colhida (ha)

Valor da produção $(\mathrm{R} \$)$

Feijão-preto

Estabelecimentos

Quantidade produzida $(\mathrm{kg})$

Área colhida (ha)

Valor da produção $(\mathrm{R} \$)$

Feijão de cor

Estabelecimentos

Quantidade produzida (kg)
354742

3203540092

1168250

1416076996

240813

512000125

527309

362509950

386821

684503518
41886

6484297927

1249266

2711970341

26487

159833030

121628

115557926

47719

595053225
$33 \%$

$76 \%$

$53 \%$ 


\begin{tabular}{|c|c|c|c|}
\hline Área colhida (ha) & 970709 & 403850 & \\
\hline \multicolumn{4}{|c|}{$\begin{array}{l}\text { Feijão-fradinho, caupi, de corda ou macáçar, } \\
\text { em grão }\end{array}$} \\
\hline Estabelecimentos & 733120 & 78472 & \\
\hline Quantidade produzida $(\mathrm{kg})$ & 952829386 & 183862430 & $84 \%$ \\
\hline Área colhida (ha) & 1901647 & 288048 & \\
\hline Valor da produção $(\mathrm{R} \$)$ & 792566452 & 158189569 & \\
\hline \multicolumn{4}{|l|}{ Mandioca } \\
\hline Estabelecimentos & 753611 & 78578 & \\
\hline Quantidade produzida $(\mathrm{kg})$ & 9906902545 & 2005726014 & $83 \%$ \\
\hline Área colhida (ha) & 1474143 & 234258 & \\
\hline Valor da produção $(\mathrm{R} \$)$ & 3298717337 & 510543788 & \\
\hline \multicolumn{4}{|l|}{ Milho em grão } \\
\hline Estabelecimentos & 1795331 & 234791 & \\
\hline Quantidade produzida $(\mathrm{kg})$ & 18872504095 & 22555105742 & $46 \%$ \\
\hline Área colhida (ha) & 6334735 & 5269266 & \\
\hline Valor da produção $(\mathrm{R} \$)$ & 5231838333 & 6152541310 & \\
\hline \multicolumn{4}{|l|}{ Soja } \\
\hline Estabelecimentos & 164015 & 53000 & \\
\hline Quantidade produzida $(\mathrm{kg})$ & 6464739230 & 39731103541 & $14 \%$ \\
\hline Área colhida (ha) & 2731883 & 15151389 & \\
\hline Valor da produção $(\mathrm{R} \$)$ & 2915979751 & 16589982706 & \\
\hline \multicolumn{4}{|l|}{ Trigo } \\
\hline Estabelecimentos & 23539 & 10488 & \\
\hline Quantidade produzida $(\mathrm{kg})$ & 473257507 & 1759997110 & $21 \%$ \\
\hline Área colhida (ha) & 323230 & 975189 & \\
\hline $\begin{array}{l}\text { Valor da produção }(R \$) \\
\text { Café arábica em grão } \\
\text { (verde) }\end{array}$ & 185379788 & 708863523 & \\
\hline Estabelecimentos & 190571 & 47929 & \\
\hline Quantidade produzida (kg) & 659527368 & 1290168152 & $34 \%$ \\
\hline Área colhida (ha) & 513394 & 777719 & \\
\hline \multicolumn{4}{|c|}{$\begin{array}{l}\text { Café canephora (robusta, conilon) em grão } \\
\text { (verde) }\end{array}$} \\
\hline Estabelecimentos & 85084 & 15761 & \\
\hline Quantidade produzida $(\mathrm{kg})$ & 259883593 & 211898954 & $55 \%$ \\
\hline Área colhida (ha) & 254464 & 142171 & \\
\hline Valor da produção $(\mathrm{R} \$)$ & 627998481 & 586222483 & \\
\hline \multicolumn{4}{|l|}{ Pecuária } \\
\hline \multicolumn{4}{|l|}{ Bovinos } \\
\hline Estabelecimentos & 2150467 & 527925 & \\
\hline
\end{tabular}


Número de cabeças em

31.12

\section{Leite de vaca}

Estabelecimentos

Quantidade produzida

(litros)

Valor da produção $(\mathrm{R} \$)$

\section{Leite de cabra}

$$
\begin{aligned}
& \text { Estabelecimentos } \\
& \text { Quantidade produzida } \\
& \text { (litros) } \\
& \text { Valor da produção }(\mathrm{R} \$)
\end{aligned}
$$

\section{Aves}

Estabelecimentos

Número de cabeças em

31.12

Ovos de galinha (dz)

Valor da produção dos ovos (R\$)

\section{Suínos}

Estabelecimentos

Número de cabeças em 31.12

Valor da produção $(R \$)$

$$
52374292
$$

123773209

$30 \%$

1090234

11849353332

5023139134

15348

23979504

29339795

2331079

584943083

450979266

711054063

1275865

220246

18411976

12777375

1482174863

8718516061

3954061864

2715

11760684

15684175

382324

558512731

$51 \%$

2330640075

$16 \%$

3401493322

1540587828
$59 \%$

Fonte: IBGE, Censo

Agropecuário 2006.

Analisando a tabela 1 percebe-se que a agricultura familiar, conforme definição da lei 11326/2006, possui participação considerável nas culturas que não necessitam de grandes escalas de produção. No entanto, deixa para agricultura não familiar um maior percentual naquelas culturas de maior escala. Arroz, por exemplo, que tem mais de $66 \%$ da produção localizada no Rio Grande do Sul (ATLAS SOCIOECONÔMICO DO RIO GRANDE DO SUL, 2011) onde os produtores atuam em grande escala, mesmo assim a agricultura familiar é responsável por $33 \%$ do total produzido. Soja, trigo, milho em grãos e na pecuária de corte, a agricultura familiar tem uma presença pequena frente ao total da produção brasileira, alcançando participação de, respectivamente, $14 \%, 21 \%, 46 \%$ e 30\%. Todavia, salienta-se que grande volume de soja é destinado à exportação, o mesmo acontece com milho e com a carne bovina, o milho ainda não é destinado em grande medida para alimentação humana, mas para fabricação de ração animal.

Dentre as culturas com maior participação da agricultura familiar estão o feijão preto, feijão de cor, feijão fradinho, feijão cupi, feijão de corda, café robusta, as aves, o leite de vaca e de cabra e os suínos. Contudo, não é possível, através desses dados afirmar que o Ministério do Desenvolvimento Agrário (MDA) esteja correto em suas considerações, mas tampouco é possível dizer que está incorreto. Mas por qual motivo? Primeiro a delimitação dada à agricultura familiar segundo a lei 11326/2006, como já foi discutido. Segundo pelas variáveis selecionadas que não consideram uma série de produtos que podem compor a alimentação do brasileiro, como os hortifrutigranjeiros, os produtos oriundos da aquicultura e assim por diante. 
Então não estariam corretas as críticas de Hoffmann (2014) ao valor de $70 \%$ dos alimentos provenientes da agricultura familiar? Não é bem o que se está colocando.

A crítica feita pelo autor faz alusão à falta de base no uso dos dados de pesquisa, pois não foi por ele encontrado um estudo que desse suporte as constatações feitas pelo MDA. Mas ele conclui: "Não é necessário criar "estatísticas" sem sentido para mostrar a importância da agricultura familiar no Brasil." (HOFFMANN 2014, p. 418). Hoffmann não deixa de salientar a importância da agricultura familiar, mas não questiona, da mesma forma que fez com o percentual apresentado pelo MDA, o conceito de agricultura familiar, que foi baseado na lei 11326/2006, e que se discutiu na seção anterior; um conceito sem base teórica alguma. Entretanto, não há demérito no trabalho, e sim um alerta para buscar mais informações antes de considerar um dado publicado como verdade. Se o limite de terra para considerar agricultor familiar fosse ampliado para além do estabelecido em lei, para algo um pouco abaixo de 100 hectares, o que pelos estudos citados por Guanziroli et al. (2001)3 ${ }^{3}$, ainda não representam o universo da agricultura familiar, mas representam apenas uma proxy, é possível chegar à dados que contribuem para atribuir a agricultura familiar um posto de grande relevância na segurança alimentar interna. Ainda, ao considerar produtos hortigranjeiros, a participação da agricultura familiar passa a assumir, em muitos casos, percentuais extremamente altos, como pode ser visto na tabela 2.

Tabela 2 - Frequência relativa do total de alguns produtos hortigranjeiros consumidos no Brasil

\begin{tabular}{l|l|l}
\hline $\begin{array}{l}\text { Produtos Selecionados } \\
\text { Conforme existência de } \\
\text { Dados }\end{array}$ & $\begin{array}{l}\text { Participação da } \\
\text { Agricultura Familiar } \\
(<100 \text { ha.) no total de } \\
\text { produção }\end{array}$ & $\begin{array}{l}\text { Participação } \\
\text { Agricultura não familiar (> } \\
100 \text { ha.) no total da } \\
\text { produção }\end{array}$ \\
\hline Alface & $98 \%$ & $02 \%$ \\
\hline Mandioquinha & $87 \%$ & $13 \%$ \\
\hline Berinjela & $93 \%$ & $07 \%$ \\
\hline Batata-doce & $97 \%$ & $03 \%$ \\
\hline Abobrinha & $83 \%$ & $17 \%$ \\
\hline Agrião & $99,8 \%$ & $0,2 \%$ \\
\hline
\end{tabular}

Fonte: Elaborado pelos autores com base em dados do Censo Agropecuário IBGE (2006)

Observando esses dados, que não objetivam refutar as conclusões de Hoffmann, nem do MDA, pode-se perceber que à medida que um conceito passa a ser compreendido de outra forma, os resultados podem se apresentar bem distintos. $\mathrm{Na}$ tabela 1 foram considerados alguns produtos que são apontados no censo agropecuário e muitos outros não estão disponíveis, o que inviabilizou uma melhor avaliação. Fora essa constatação, olhando pela lei 11326/2006, alguns produtos consumidos pelos brasileiros possuem uma elevada participação da agricultura familiar, como feijão preto (76\%), feijão de cor (53\%), feijão fradinho (84\%) e mandioca (83\%), apresentados na Tabela 1.

Os dados, qual for a definição utilizada, mostram que a agricultura familiar é significativa para a economia, pois tem uma produção presente na mesa dos brasileiros, o que afeta a segurança alimentar de um país. É importante ressaltar, que, mesmo não dedicando grande parte ao mercado, o autoconsumo faz parte das

\footnotetext{
${ }^{3}$ Os Estudos da FAO/INCRA citados por Guanziroli et al. (2001) apontam área total menor ou igual a quinhentos hectares para as regiões Sudeste e Sul e mil hectares para as demais regiões. Novos estudos feitos por essas instituições modificam esses dados com melhor distribuição nas regiões brasileiras, mas não inferior a 200 hectares onde existe predominância de mão de obra familiar.
} 
estatísticas para composição da alimentação interna do país e é uma das características da lógica por trás da produção agrícola familiar. De acordo com Oliveira et al. (2010) a agricultura familiar apresenta grande relevância para a economia nacional, representando importante papel na geração de empregos no meio rural, e garantindo parcela considerável da segurança alimentar brasileira. E os dados levantados comprovam essa afirmação.

Ainda assim, esse modo de produção sempre foi "esquecido" pelos formuladores de políticas públicas ao longo dos anos, como é observado por Mattei (2014) que coloca que perpassando todo o período imperial, e também nos períodos posteriores, a agricultura ligada a forma camponesa não recebeu praticamente nenhum apoio governamental para se desenvolver de forma adequada. Ainda de acordo com o autor, as políticas públicas desenvolvidas sempre privilegiaram os setores mais capitalizados.

No início da década de 1990 ainda não se verificava uma política de apoio ao agricultor familiar. Foi a partir de 1996, com a criação do PRONAF (Programa Nacional de Fortalecimento da Agricultura Familiar), que o pequeno produtor passa a poder recorrer a um programa de assistência. Conforme descreve Mattei (2014), a criação do Pronaf visava:

“(...) atender a uma antiga reivindicação das organizações dos trabalhadores rurais, as quais demandavam a formulação e a implantação de políticas de desenvolvimento rural específicas para o maior segmento da agricultura brasileira, porém o mais fragilizado em termos de capacidade técnica e de inserção nos mercados agropecuários. Deve-se ressaltar que neste processo os atores sociais rurais, através de suas organizações e de suas lutas, desempenharam um papel decisivo na implantação do programa, considerado uma bandeira histórica dos trabalhadores rurais, pois permitiria a estes o acesso aos diversos serviços oferecidos pelo sistema financeiro nacional, até então negligenciados aos agricultores familiares." (MATTEI, 2014, p.71)

O Pronaf tornou-se um instrumento de suma importância para o desenvolvimento rural do país, pois proporciona às necessidades da agricultura familiar um tratamento apropriado. "Com a intervenção na área de crédito, de infraestrutura, de pesquisa e de assistência técnica comprova a importância de políticas de desenvolvimento rural que enfatizam a agricultura familiar como atividade prioritária [...]" (MATTEI, 2014).

Oliveira et al. (2010) contribuem afirmando que o apoio à agricultura familiar em uma sociedade capitalista representa-se como essencial. O Governo tem por responsabilidade o dever de realizar políticas públicas que atendam as carências desse grupo social, atuando como regulador do mercado e também do acesso a crédito. "O interesse do Estado em manter esse sistema é devido, sobretudo, a importância da agricultura familiar no ambiente econômico capitalista" (OLIVEIRA et al. 2010, p. 6).

Para Guilhoto et al. (2007, p.13), a agricultura familiar é sempre lembrada por sua importância na geração de alimentos, especialmente para o autoconsumo. Para o autor a agricultura familiar preocupa-se mais com questões sociais do que econômicas. No entanto, esse modo de produção contribui de forma efetiva na "redução do êxodo rural, e na formação de riqueza para o setor agropecuário, e consequentemente para a riqueza do país". 
Ficou claro, nessa subseção, que a agricultura familiar exerce um papel importante na economia e na segurança alimentar brasileira. Que apesar das críticas a alguns dados que buscam ressaltar sua importância, é possível, mesmo considerando uma lei que limita em 4 módulos fiscais a caracterização do agricultor de base familiar - sem base teórica para tanto - perceber a forte presença da produção familiar no consumo interno do país.

\title{
4.2 AGRICULTURA FAMILIAR: RELEVÂNCIA PARA O MATO GROSSO DO SUL E O MUNICÍPIO DE PONTA PORÃ
}

O centro-oeste do país tem como principal atividade econômica o agronegócio. Para Guilhoto et al. (2007), o embasamento da economia dessa região se dá no setor rural, tendo como predominante o "segmento patronal", que é compreendido por grandes propriedades produtoras, e baseado no modelo plantation, com destaque à monocultura, de modo a atender o mercado internacional. Para Guanziroli et al. (2001) a região centro-oeste apresenta a menor presença de agricultores familiares no Brasil; no entanto, seu papel foi de extrema importância na ocupação de território e na estruturação da economia.

Mato Grosso do Sul é fruto da divisão do estado de Mato Grosso e não escapa das características do Centro-Oeste brasileiro. O município de Ponta Porã, fica localizado na região da fronteira-oeste do Estado de Mato Grosso do Sul e é o município que abriga o maior assentamento da reforma agrária da América do Sul, portanto, com grande presença da agricultura familiar.

Em Mato Grosso do Sul, de acordo com o Ministério de Desenvolvimento Agrário - MDA (2011) citado por Sangalli e Schlindwein (2013), 60\% dos alimentos produzidos no estado são resultantes da agricultura familiar.

\begin{abstract}
Ainda que, com índices de produtividade mais modestos, a agricultura familiar contribui com o agronegócio do estado e do país, principalmente com a ocupação e a geração de renda a um grande número de famílias de agricultores que dependem da terra para a sua sobrevivência. (SANGALLI e SCHLINDWEIN, 2013, p.84)
\end{abstract}

A tabela 3 apresenta dados referentes aos números de estabelecimentos e hectares, discriminado por agricultura familiar, em conformidade com a lei $\mathrm{n}^{\circ}$ 11.326/2006, e agricultura não familiar. O que se observa a primeira vista, é um valor inferior de hectares compreendido pela agricultura familiar quando comparado à agricultura não familiar, evidencia de um processo de concentração de terras pela agricultura não familiar. Mas isso também pode estar associado ao fato de se considerar agricultura familiar com apenas 4 módulos fiscais, que para a região Centro-Oeste gira em torno de 240 a 400 hectares. No entanto, no que se refere ao número de estabelecimentos, nota-se uma dinâmica diferente, isso tanto a nível nacional quanto regional.

Em número de estabelecimentos ocupados pela agricultura familiar, o centro-oeste representou, em $2006,4,97 \%$ do total de estabelecimentos em relação ao Brasil. O valor sobe para $12,41 \%$ quando analisada a agricultura não familiar na participação do centro-oeste no valor total nacional. Nos anos de 2006 a agricultura familiar na região centro-oeste compreendeu $11,67 \%$ do total da agricultura familiar brasileira em relação à área em hectares. A participação para a agricultura não familiar da região apresentou percentual de $37,86 \%$ relacionado ao total do país, nos anos de 2006, conforme a tabela 3. 
Em análise ao Mato Grosso do Sul, nota-se participação relativa do estado no que concerne ao número de estabelecimentos atribuídos à agricultura familiar, na região centro-oeste, com participação de 18,91\%, em 2006. Mato Grosso do Sul esteve à frente apenas do Distrito Federal $(0,84 \%)$, os demais estados da região, Goiás e Mato Grosso, apresentaram no mesmo ano, respectivamente $40,70 \%$ e $39,54 \%$ do número de estabelecimentos na região centro-oeste. No tocante à área em hectares, a participação do estado sul-mato-grossense em relação ao centrooeste representou $12,66 \%$.

A agricultura não familiar no estado de Mato Grosso do Sul, representou participação no centro-oeste de $23,69 \%$ do total de estabelecimentos da região, e $30,30 \%$ da ocupação das áreas.

Tabela 3 - Estabelecimentos e área da agricultura familiar, Brasil e outras regiões - 2006

\begin{tabular}{|c|c|c|c|c|}
\hline \multirow{2}{*}{$\begin{array}{c}\text { Grandes Regiões, } \\
\text { Unidades da Federação e } \\
\text { Município. }\end{array}$} & \multicolumn{2}{|c|}{ Agricultura familiar - Lei $n^{\circ} 1.326$} & \multicolumn{2}{|c|}{ Não familiar } \\
\hline & Estabelecimentos & Área (ha) & Estabelecimentos & Área (ha) \\
\hline Brasil & 4366267 & 80102694 & 809369 & 253577343 \\
\hline Norte & 412666 & 16611277 & 63112 & 38924487 \\
\hline Nordeste & 2187131 & 28315052 & 266929 & 47759359 \\
\hline Sudeste & 699755 & 12771299 & 222342 & 42166474 \\
\hline Sul & 849693 & 13054511 & 156510 & 28726492 \\
\hline Centro-Oeste & 217022 & 9350556 & 100476 & 96000530 \\
\hline Mato Grosso & 85815 & 4837564 & 27172 & 43851146 \\
\hline Goiás & 88326 & 3317908 & 47366 & 22818173 \\
\hline Distrito Federal & 1824 & 10867 & 2131 & 240453 \\
\hline Mato Grosso do Sul & 41057 & 1184217 & 23807 & 29090759 \\
\hline Ponta Porã & 3088 & 46219 & 610 & 365098 \\
\hline
\end{tabular}

Fonte: Censo Agropecuário 2006

O município pontaporanense, em 2006, contou com maior número de estabelecimentos ocupados pela agricultora familiar, quando comparado ao segmento não familiar, como apresenta a tabela 2. O que se destaca, a partir da análise de participação do município em relação ao estado de Mato Grosso do Sul, é maiores percentuais para a agricultura familiar, tanto no tocante "estabelecimentos", quanto em área, medida em "hectares".

Os estabelecimentos da agricultura familiar em Ponta Porã correspondem a $7,52 \%$ da participação total do estado. Resultado este quase três vezes maior, quando analisada a participação da agricultura não familiar do município, em relação ao total da agricultura não familiar de Mato Grosso do Sul, 2,56\% em 2006. As áreas ocupadas (hectares) pela agricultura familiar em Ponta Porã, com relação ao total do estado sul-mato-grossense, também se demonstraram mais elevadas em comparação a não familiar, com 3,90\% contra 1,26\% respectivamente. Esses resultados podem ser atribuídos às peculiaridades do município, que tem como distrito um dos maiores assentamentos do Brasil, o assentamento Itamarati. 
No assentamento Itamarati, localizado no município de Ponta Porã, de acordo com Santos e Brandão (2015), há um projeto intitulado Centro Comunitário de Produção (CCP), no qual é feito "o resfriamento do leite produzido por agricultores familiares, atendendo dezesseis famílias do Assentamento".

Ao analisar o deslocamento da mão de obra dos produtores antes e após o funcionamento do CCP, observou-se que, entre as famílias dos 16 produtores que são beneficiários, houve um deslocamento para o trabalho agrícola e uma consequente diminuição da dedicação a atividades de trabalho urbano: a) antes do CCP somente $62,5 \%$ destas famílias possuíam algum membro trabalhando com produção, venda ou troca de produtos agrícolas e; b) após o CCP ocorreu redução no percentual de famílias que possuíam algum membro envolvido em atividades de trabalho urbanas (de $43,8 \%$ para $12,5 \%$ ). (SANTOS e BRANDÃO, 2015, p. 3)

Diante disso, dado que o meio de produção de que dispõem as famílias de um assentamento, como o Itamarati, por exemplo, é a terra, deve haver incentivos e subsídios para que ocorra o bom aproveitamento desse meio de produção, pois é da terra que essas famílias tiram seu sustento, podendo ser através da produção para autoconsumo ou até por meio da venda de seus excedentes.

A agricultura familiar no município de Ponta Porã também contribui com os seguintes produtos (IBGE, 2014; IBGE, 2014a.):

- Lavoura Permanente: banana (25 toneladas/ano e com valor da produção de $\mathrm{R} \$ 38 \mathrm{mil}$ ); café (8 toneladas/ano e valor da produção de $\mathrm{R} \$ 24$ mil); erva-mate (840 toneladas/ano e valor da produção de $R \$ 216$ mil); laranja (80 toneladas/ano e valor da produção de $\mathrm{R} \$ 56$ mil); maracujá (50 toneladas /ano e valor da produção de $R \$ 55$ mil); uva (40 toneladas/ano e valor da produção de $R \$ 144$ mil), etc. (IBGE, 2014, Produção Agrícola Municipal - Lavoura Permanente)

- Lavoura temporária: mandioca (6450 toneladas/ano e valor da produção de $R \$ 1764$ mil); melancia (650 toneladas/ano e valor da produção de $R \$ 240$ mil); tomate (250 toneladas/ano e valor da produção de $\mathrm{R} \$ 470$ mil); etc. (IBGE, 2014, Produção Agrícola Municipal - Lavoura temporária)

Também há produção de soja, arroz, milho, trigo, tricale, aveia nas unidades de produção familiar, porém, é de difícil precisão do montante que pertence à agricultura familiar dessas culturas, pelo fato de áreas pertencentes à agricultura familiar utilizadas para produção desses produtos serem utilizadas por produtores não familiares, por meio de arrendamentos não legais. .

A pecuária, tanto em produção de peixes como na criação de gado de corte e leite, caprinos, bicho da seda, suínos, bubalinos, abelhas, etc. tem a participação da agricultura familiar. A aquicultura, no Brasil, é de responsabilidade de pequenos produtores, com menos de 100ha. Essa atividade é importante na região de Ponta Porã, principalmente com a criação de Carpa (3000kg), Pacu e Patinga (140000 kg), Pintado, Cachara e Pintachara, Surubim (33000kg), Tambacu e Tambatinga $(60000 \mathrm{~kg})$, Tilápia $(50000 \mathrm{~kg})$ e alevinos (200 milheiros), tudo perfaz um valor da produção de $R \$ 1.343 .000,00$.

Uma maior diversidade de produção é apresentada pela agricultura familiar que a agricultura patronal na região Centro-Oeste e no município sul-matogrossense de Ponta Porá. Essa possibilidade de diversidade, pode ser explorada ainda mais, possibilitando maior renda e o sustento de maior número de famílias. 


\begin{abstract}
"É importante realçar o papel decisivo que a agricultura familiar desempenha para além dos aspectos meramente produtivos. (...) Em regiões em que predomina este tipo de agricultura são gritantes as diferenças, comparativamente às áreas dominadas pelo agronegócio, cujo centro dinâmico é dado pelas commodities produzidas em larga escala e voltadas aos mercados internacionais. Duas diferenças são visíveis: a maior preservação dos recursos naturais e um espaço físico ocupado com gente". (MATTEI, 2014, p. 78)
\end{abstract}

A agricultura familiar apresenta-se como essencial no que se refere às questões sociais. É importante estratégia para conter a emigração do meio rural, além de minimizar as desigualdades entre a população rural e urbana. Assim como finaliza Guilhoto et al. (2007 p. 13) "este setor deve ser encarado como um forte elemento de geração de riqueza, não apenas para o setor agropecuário, mas para a própria economia do país".

Apesar do Centro-Oeste, especialmente de Mato Grosso do Sul, apresentar menor número de estabelecimentos familiares em comparação com o restante do Brasil, a agricultura que segue essa lógica se mostra importante, da mesma forma que para o país. Ponta Porã, como município sul-mato-grossense com maior incidência de agricultores familiares, também em virtude do Assentamento Itamarati, tem nela a possibilidade de diversificação agrícola o que é importante para economia municipal, não só dos núcleos familiares rurais.

\title{
5. CONCLUSÃO
}

Este trabalho teve como objetivo analisar a importância da agricultura familiar para o Brasil e em particular para o estado de Mato Grosso do Sul e o município de Ponta Porã, que possui em seu território o maior assentamento da reforma agrária do Brasil e da América do Sul. Através de métodos de levantamento em publicações e documentos do Instituto Brasileiro de Geografia e Estatística, pode-se constatar a relevância do modo de produção familiar tanto para o Brasil, quanto para o Mato Grosso do Sul e Ponta Porã.

Fica evidente nesse trabalho que a Agricultura Familiar é responsável por percentuais significativos do alimento consumido no Brasil, estudo anterior que questionava o percentual estabelecido de $70 \%$ de participação, não considerou uma série de produtos que são consumidos diariamente pela população e, também, baseou a analise em uma definição questionável da agricultura familiar, que foi estabelecida unicamente para fins de financiamento. Neste estudo, apesar da dificuldade de precisão do que é agricultor familiar, mostra-se com clareza que ao assumir um maior rol de produtos e diferentes conceitos, é possível estabelecer participação maior do que a divulgada por parte da agricultura familiar na mesa do brasileiro, sendo superior a $90 \%$ em alguns produtos.

No entanto, ficou claro que o grau de importância dada à agricultura familiar depende da forma como se observa esse modo de produção. Primeiro, pela própria definição do que vem a ser agricultura familiar. Estudos que analisaram a agricultura familiar alicerçando suas considerações no que foi definido como agricultor familiar, através dos preceitos da lei 11326/2006, possuem claro viés nos seus resultados; pois, não há consistência teórica na definição estabelecida por ela. Entretanto, fica uma lacuna na identificação do tamanho que se deve atribuir às unidades familiares e, da mesma forma, identificar com exatidão os produtos oriundos dessa lógica produtiva, ficando aqui, sugestões para estudos futuros. 


\section{REFERÊNCIAS}

ALFATIN, I. Reflexões sobre o conceito de agricultura familiar. Brasília: CDS/UnB, 2007.

ATLAS SOCIOECONÔMICO DO RIO GRANDE DO SUL. Economia. Arroz. 2011. Disponível em: http://www.atlassocioeconomico.rs.gov.br/conteudo.asp?cod_menu filho=819\&cod menu=817\&tipo_menu=ECONOMIA\&cod_conteudo=1490. Acesso em: 03 jul. 2016.

BRASIL, Lei $n^{0}$ 11326. Estabelece as diretrizes para a formulação da Política Nacional da Agricultura Familiar e Empreendimentos Familiares Rurais. 24 de julho de 2006. Congresso Nacional. Disponível em: http://www.camara.gov.br/sileg/integras/837541.pdf. Acesso em: 26 jun. 2016.

CONTI, I. L.; BAZOTTI, A.; RADOMSKY, G. F. Agricultura familiar e segurança alimentar e nutricional: um estudo sobre a relação produção-consumo nos municípios de Toledo (PR) e Contagem (MG). Extensão Rural, Santa Maria, v.22, n.1, p.56-86, jan./mar. 2015. Disponível em: https://periodicos.ufsm.br/extensaorural/article/view/11935/pdf. Acesso em 03 jul. 2016.

FAO, Organização das Nações Unidas para a Alimentação e Agricultura. (2014). O que é Agricultura Familiar? Disponível em: http://www.fao.org/family-farming2014/home/what-is-family-farming/pt/. Acesso em: 26 jun 2016.

GUANZIROLI, C. E.; BUAINAIN, A. M.; SABBATO, A. Dez anos de evolução da agricultura familiar no Brasil: (1996 e 2006). Rev. Econ. Sociol. Rural v.50 n.2 Brasília, apr./jun. 2012.

GUANZIROLI, C. et al. Agricultura familiar e reforma agrária no século XXI. Rio de Janeiro, Garamond, 2001.

GUILHOTO, J.M. et.al. A importância da agricultura familiar no Brasil e em seus Estados. ENCONTRO DA ANPEC: área 10, Economia Agrícola e do Meio Ambiente, 2007.

HOFFMANN, R. A agricultura familiar produz $70 \%$ dos alimentos consumidos no Brasil? Segurança Alimentar e Nutricional, Campinas, 2014.

IBGE - INSTITUTO BRASILEIRO DE GEOGRAFIA E ESTATÍSTICA. Censo Agropecuário 2006. Disponível em: http://www.ibge.gov.br/home/estatistica/economia/agropecuaria/censoagro/agri_famil iar_2020_2/default.shtm. Acesso em: 26 de jun. 2016.

IBGE - INSTITUTO BRASILEIRO DE GEOGRAFIA E ESTATÍstICA. Produção Agrícola Municipal. Lavoura temporária. 2014. Disponível em: http://www.cidades.ibge.gov.br/xtras/temas.php?lang=\&codmun=500660\&idtema=14 9\&search=mato-grosso-do-sul|ponta-pora|producao-agricola-municipal-lavouratemporaria-2014. Acesso em: 26 de jun. 2016. 
IBGE - INSTITUTO BRASILEIRO DE GEOGRAFIA E ESTATÍSTICA. Produção Agrícola Municipal. Lavoura permanente. 2014a. Disponível em: http://www.cidades.ibge.gov.br/xtras/temas.php?lang=\&codmun=500660\&idtema $=14$ $8 \&$ search=mato-grosso-do-sul|ponta-pora|producao-agricola-municipal-lavourapermanente-2014. Acesso em: 26 de jun. 2016.

MATTEI, L. O papel e a importância da agricultura familiar no desenvolvimento rural brasileiro contemporâneo. Rev. Econ. NE, Fortaleza, v. 45, p. 71-79, 2014.

MINISTÉRIO DO DESENVOLVIMENTO AGRÁRIO (MDA). SFA - Importante para o desenvolvimento dos municípios e dos agricultores familiares. 2014. Disponível em http://www.mda.gov.br/sitemda/secretaria/saf-suasa/importante-para-o-

desenvolvimento-dos-munic\%C3\%ADpios-e-dos-agricultores-familiares. Acesso em: 03 jul. 2016.

MOURA, M. A. T. Comparativo entre agricultura familiar teórica e normativa no Brasil. UFRGS, Porto Alegre, 2011.

OLIVEIRA, N, S. Agricultura familiar do agronegócio do leite em Rondônia, importância e características. In: 48 SOCIEDADE BRASILEIRA DE ECONOMIA, ADMINISTRAÇÃO E SOCIOLOGIA RURAL, 48., 2010, Campo Grande. Anais... Campo Grande, UFMS, 2010.

SANGALLI, A. R.; SCHLINDWEIN, M. M. A contribuição da agricultura familiar para o desenvolvimento rural de mato grosso do sul - Brasil. REDES - Rev. Des. Regional, Santa Cruz do Sul, v. 18, n. 3, p. 82 - 99, set/dez. 2013.

SANTOS, N C.; BRANDÃO, A. A. P. CENTRO COMUNITÁRIO DE PRODUÇÃO DE PONTA PORÃ-MS: efeitos positivos de um projeto de geração de renda sobre questões de gênero, saúde e educação? In: VII JORNADA INTERNACIONAL DE POLÍTICAS PÚBLICAS, UFMA, 2015.

SCHNEIDER, S. Teoria Social, Agricultura familiar e Pluriatividade. RBCS, v. $18 \mathrm{n}$. 51, fev. 2003.

STALOCH, R.; ROCHA, I. O. Agricultura familiar e a permanência no campo: a experiência de um projeto realizado e a percepção dos jovens sobre o município de Santa Terezinha (Santa Catarina). Extensão Rural, Santa Maria, v.25, n.3, p. 89112, jul./set. 2018. Disponível em: https://periodicos.ufsm.br/extensaorural/article/view/36130/pdf. Acesso em: 18 jul. 2019.

WANDERLEY, M. N. Agricultura familiar e campesinato: rupturas e continuidade. Estudos Sociedade e Agricultura (UFRJ), Rio de Janeiro, v. 21, p. 42-61, 2003. 